\title{
Fault-Plane Determination of the 18 April 2008 Mount Carmel, Illinois, Earthquake by Detecting and Relocating Aftershocks
}

\author{
by Hongfeng Yang, Lupei Zhu, and Risheng Chu
}

\begin{abstract}
We developed a sliding-window cross-correlation (SCC) detection technique and applied the technique to continuous waveforms recorded by the Cooperative New Madrid Seismic Network stations following the 18 April 2008 Illinois earthquake. The technique detected more than 120 aftershocks down to $M_{\mathrm{L}} 1.0$ in the 2 week time window following the mainshock, which is three times more than the number of aftershocks reported by the seismic network. Most aftershocks happened within $24 \mathrm{hrs}$ of the mainshock. We then relocated all events by the double-difference relocation algorithm. Accurate $P$ - and $S$-wave differential arrival times between events were obtained by waveform cross correlation. After relocation, we used the L1 norm to fit all located events by a plane to determine the mainshock fault plane. The best-fit plane has a strike of $292^{\circ} \pm 11^{\circ}$ and dips $81^{\circ} \pm 7^{\circ}$ to the northeast. This plane agrees well with the focal mechanism solutions of the mainshock and four largest aftershocks. By combining the aftershock locations and focal mechanism solutions, we conclude that the 18 April earthquake occurred on a nearly vertical left-lateral strikeslip fault orienting in the west-northwest-east-southeast direction. The fault coincides with the proposed left-stepping Divide accommodation zone in the La Salle deformation belt and indicates reactivation of old deformation zone by contemporary stresses in the Midcontinent.
\end{abstract}

Online Material: Local magnitudes, and new and catalog locations of the 2008 Illinois earthquake sequence.

\section{Introduction}

On 18 April 2008, a moderate earthquake $\left(M_{\mathrm{w}}\right.$ 5.2) occurred in Mount Carmel, southeastern Illinois, and caused minor structural damage in the surrounding area. It was followed by numerous aftershocks in the next 2 weeks, including two events with magnitudes of $M_{\mathrm{w}} 4.6$ and 4 (Herrmann et al., 2008). This series of earthquakes occurred within the Wabash Valley seismic zone (WVSZ), which covers a large area of southeastern Illinois and southwestern Indiana (Fig. 1) (Nuttli, 1979; Ault and Sullivan, 1982; Ault et al., 1985). In the past 40 yrs, several moderate earthquakes have occurred in the same region. The largest event was the 9 November 1968 earthquake with an $m_{\mathrm{b}}$ of 5.5 that was felt as far as St. Louis and Chicago. Stauder and Nuttli (1970) located it at $88.48^{\circ} \mathrm{W}, 37.95^{\circ} \mathrm{N}$ with a focal depth of $25 \mathrm{~km}$. Its focal mechanism solution showed that it was due to a northtrending thrust motion (Stauder and Nuttli, 1970; Herrmann, 1973). The 10 June 1987 earthquake with an $m_{\mathrm{b}}$ of 4.9 (Taylor et al., 1989; Langer and Bollinger, 1991) and the 18 June 2002 earthquake with an $m_{\mathrm{b}}$ of 5.0 (Kim, 2003) also caused minor damage. Both events exhibited strike-slip focal mechanisms. A study of liquefaction features in Holocene sediments provided evidence of large prehistoric earthquakes with $m_{\mathrm{b}}$ of $6.2 \sim 6.7$ in the region (Obermeier et al., 1991). By modeling stress changes caused by the 1811-1812 New Madrid earthquake sequence and using recent earthquake distribution, Mueller et al. (2004) suggested that the third event $(01 / 23 / 1812)$ in the sequence occurred in the WVSZ, $200 \mathrm{~km}$ northeast from the New Madrid seismic zone (NMSZ). The WVSZ and the NMSZ are the dominant sources of hazard in the central and eastern United States, and therefore, it is imperative to map the resulting hazard for purposes of mitigating their effects (Nuttli, 1979; Frankel et al., 1996, 2002; Eagar et al., 2006).

Compared to the NMSZ, the WVSZ has so far received far less attention, partly because of the lower seismicity. The main geological feature associated with the WVSZ is the 90-km-long and 50-km-wide Wabash Valley fault system (Fig. 1), which consists of a network of northeast-southwesttrending faults (Ault and Sullivan, 1982; Ault et al., 1985; Rene and Stanonis, 1995; Woolery, 2005). The faults were first discovered by petroleum exploration drilling in the early 1900s and were then widely studied by geological 


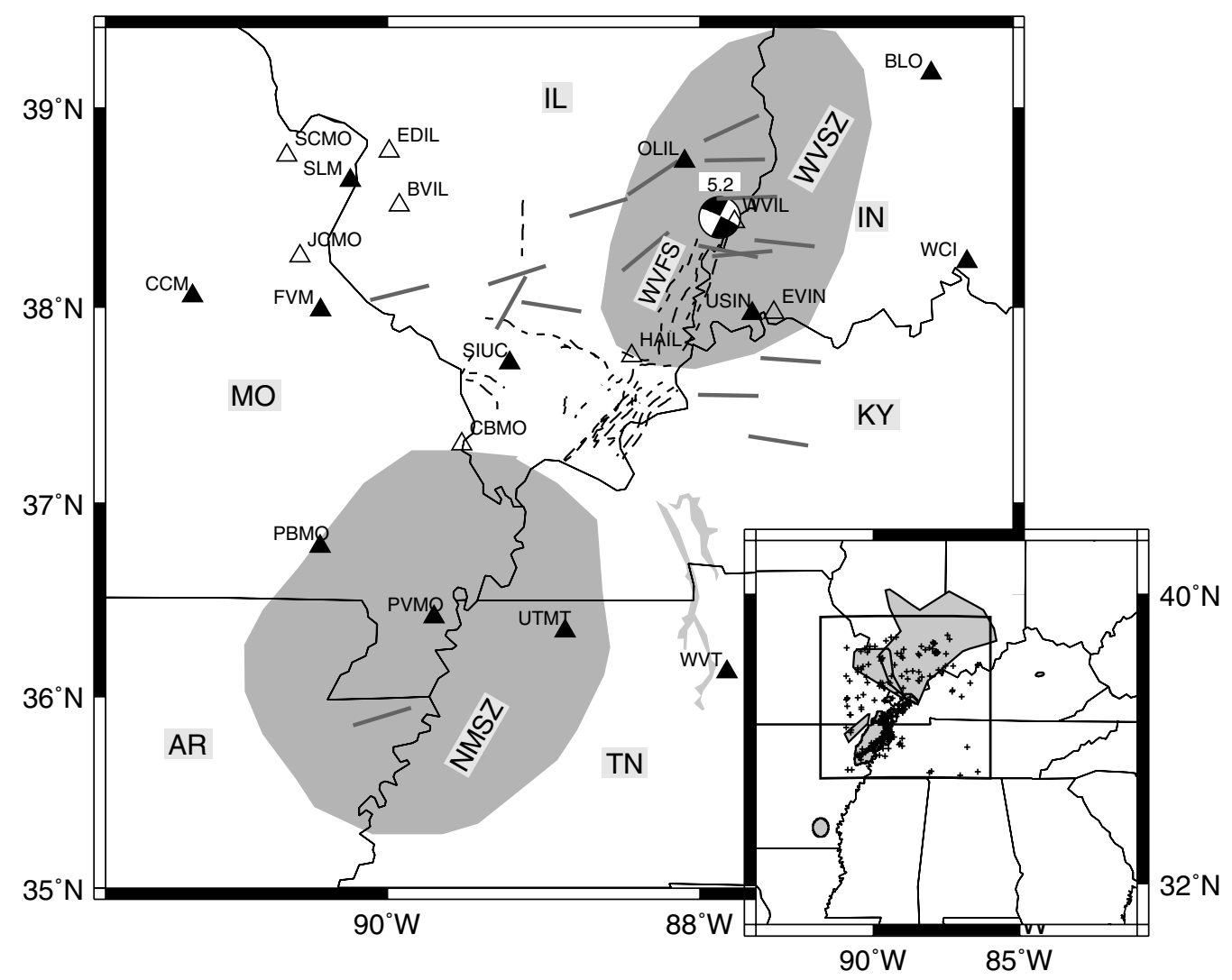

Figure 1. Symbol represents the epicenter of the 18 April 2008 Mount Carmel, Illinois, earthquake. The shaded areas are the WVSZ and NMSZ, from Gomberg and Schweig (2002). Dashed lines represent faults and graben structures in southern Illinois, from Illinois State Geological Survey (ISGS) (1995). Line segments show the stress orientation in the region (Heidbach et al., 2008). Black triangles denote broadband seismic stations of CNMSN and open triangles denote strong-motion stations. Inset: black box is the study area. Black crosses represent seismicity in the region, from the National Earthquake Information Center (NEIC) catalog (1973-2008) and the catalog of Eastern, Central, and Mountain States of the United States (1534-1986). Shaded areas are liquefaction features in the region, including Wabash Valley liquefaction features, St. Louis-Cape Girardeau liquefaction features, and Western Lowlands liquefaction features (U.S. Geological Survey [USGS] and ISGS, 2006). WVFS, Wabash Valley fault system.

and geophysical investigations (Pratt et al., 1992; McBride et al., 2002; Duchek et al., 2004; McBride et al., 2007). Previous studies suggested that those faults were high-angle normal faults that formed in late Pennsylvanian or younger and pre-Pleistocene time (Rene and Stanonis, 1995; Woolery, 2005). But origins of those faults still remain enigmatic (Marshak and Paulsen, 1996; Wheeler and Ravat, 2002). Only a few faults have been associated with known earthquakes. For example, McBride et al. (2007) suggested that the $1968 m_{\mathrm{b}} 5.5$ and the $1987 m_{\mathrm{b}} 4.9$ earthquakes occurred on preexisting deformation zones reactivated by contemporary stresses. Because none of the faults has surface expression, seismic methods have to be applied to investigate the faults down to the seismogenic depth.

A near real-time moment tensor solution of the 2008 earthquake showed an almost pure strike-slip focal mechanism (Herrmann et al., 2008). In addition to the mainshock, we computed moment tensor solutions for the four largest aftershocks by the cut and paste method (Zhu and Helmberger, 1996). All five earthquakes have similar strike-slip focal mechanisms indicating that the strike of the fault is either northeast-southwest or northwest-southeast. Because of the ambiguity of the fault plane from moment tensor solutions, other information has to be used to determine the true fault plane. Accurate locations of aftershocks can give good constraint on fault-plane parameters (strike, dip, and depth). In this study, we relocated the mainshock and its aftershocks to determine the fault plane of the mainshock. In order to delineate the fault plane, we need a large number of aftershocks. The Center for Earthquake Research and Information (CERI) located 30 aftershocks for the Mount Carmel earthquake series in the first 2 weeks. Those events were detected by the traditional short-term average (STA) over long-term average (LTA) method. However, small events below the threshold were likely missed by this method. In this work, we first developed a sliding-window cross-correlation (SCC) technique to detect aftershocks and applied it to the continuous data. We then relocated all detected events by the double-difference algorithm and determined the fault plane using the locations of relocated events. 


\section{Method}

Seismic events are typically detected by comparing the amplitude power over a short-time window to that over a long-time window. This is the so-called STA/LTA power detector originally proposed by Freiberger (1963). Another way to detect events is to cross-correlate seismic waveform data with waveform records of known events (template events). That is called the matched-signal detector (van Trees, 1968; Whalen, 1971). This method has so far received little attention because it requires a template event and the sensitivity of detection highly depends on the similarity between the template and the signal in the incoming waveform data. The matched-signal detector is very useful to detect low signal-to-noise ratio (SNR) signal and unusual seismic events such as tremor (Shelly et al., 2007a). With the array-based beam forming technique, this method can detect events with magnitudes as low as -1 (Gibbons and Ringdal, 2006).

Let $f(t)$ and $g(t)$ represent two time series; the conventional nonnormalized cross correlation of the two is

$$
C(t)=f(t) * g(t)=\int_{-\infty}^{\infty} f(t+\tau) g(\tau) d \tau
$$

If we assume $f(t)$ is a continuous waveform of ground motion and $g(t)$ is the waveform of a template event with a finite length of $T$, we can write the previous equation as

$$
C(t)=f(t) * g(t)=\int_{-T}^{0} f(t+\tau) g(\tau) d \tau .
$$

Note that only $f(\tau)$ between $t-T$ and $t$ are needed to compute $C(t)$. It is equivalent to sliding the template signal, $g(t)$, over the infinitely long waveform $f(t)$. We call it SCC.

If we apply the SCC to the three channels (e.g., BHZ, BHE, or BHN) separately, we face a problem of inconsistent detections by different channels. Different numbers of detections may be obtained on different channels depending on the SNR of the continuous waveform. Even if all the channels successfully detect the same event, they may not agree with each other on the detection time exactly. To solve the problem, we revised equation (2) so that the SCC can be applied to three components of waveform data simultaneously. Let $\mathbf{f}(t)$ and $\mathbf{g}(t)$ represent the three-component vectors of the ground motion and the template signal, respectively; their inner product is defined as

$$
\langle\mathbf{f} \mid \mathbf{g}\rangle=\int_{-T}^{0} \mathbf{f}(t+\tau) \cdot \mathbf{g}(\tau) d \tau
$$

and the normalized cross-correlation coefficient is

$$
C(t)=\frac{\langle\mathbf{f} \mid \mathbf{g}\rangle}{\sqrt{\langle\mathbf{f} \mid \mathbf{f}\rangle\langle\mathbf{g} \mid \mathbf{g}\rangle}} .
$$

One obvious advantage is that there will be only one detection time for each detection. False detections are also reduced because we include all phase information from the three channels.

An example of detection by the SCC using threecomponent data simultaneously is shown in Figure 2. The three traces on the top represent the three channels of a 5-min-long seismogram at a broadband seismic station OLIL. The bottom trace is output cross-correlation coefficients of the SCC. We used a 15-sec-long waveform of an $M_{\mathrm{L}} 3.3$ aftershock as the template (Fig. 3). Five events were detected in the 5-min-long waveforms by setting the crosscorrelation coefficient threshold value to be 0.6. All detected events have relatively clear $S$-wave arrivals but only two events (nos. 2 and 5) have recognizable $P$-wave arrivals. Figure 3 shows that the SCC detector can detect low SNR events (e.g., event nos. 3, 4, and 6) because it uses all phase information from the three channels. In contrast, the STA/LTA detector is likely to miss those low SNR events. Moreover, the SCC detector can estimate the magnitude of a detected event by using the amplitude ratio $A / A_{t}$ between the detected event and the template,

$$
m=m_{t}+\log \left(A / A_{t}\right)
$$

where $m_{t}$ is the magnitude of the template event.

\section{Data and Results}

Data used in the aftershock detection were collected from broadband seismic stations of the Cooperative New Madrid Seismic Network (CNMSN). Three stations have recording sample rates of 40 samples per second and others are 20 samples per second. We retrieved the continuous data from 16 April to 2 May 2008 and saved them in 1-day-long recordings. A band-pass filter from 0.3 to $8 \mathrm{~Hz}$ was applied

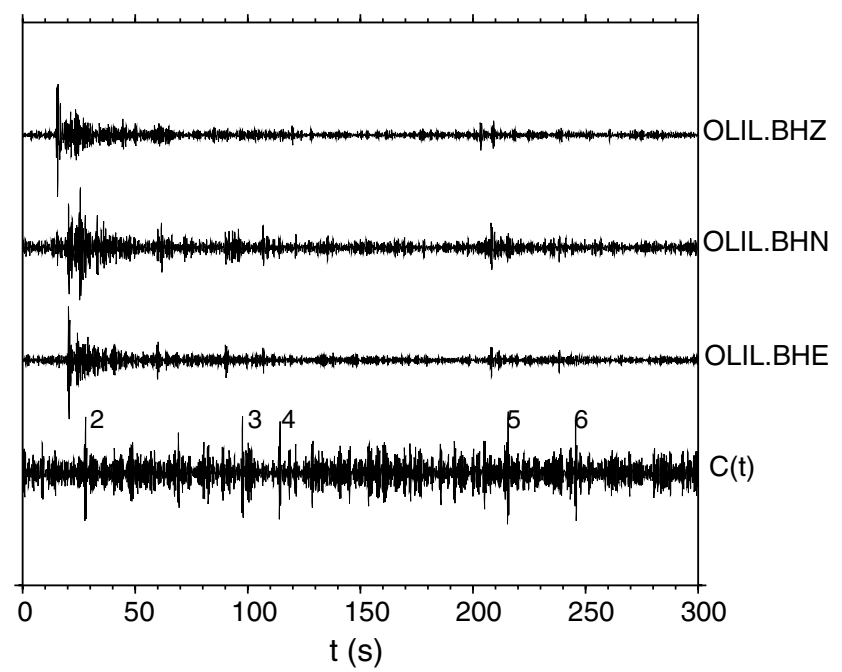

Figure 2. An example of SCC detection. The three traces on the top are channels of velocity recordings of station OLIL. The trace at the bottom is the cross-correlation coefficient of the SCC detection using an $M_{\mathrm{L}} 3.3$ template event, see Figure 3. Numbers marked on the trace correspond to events detected by the SCC. 


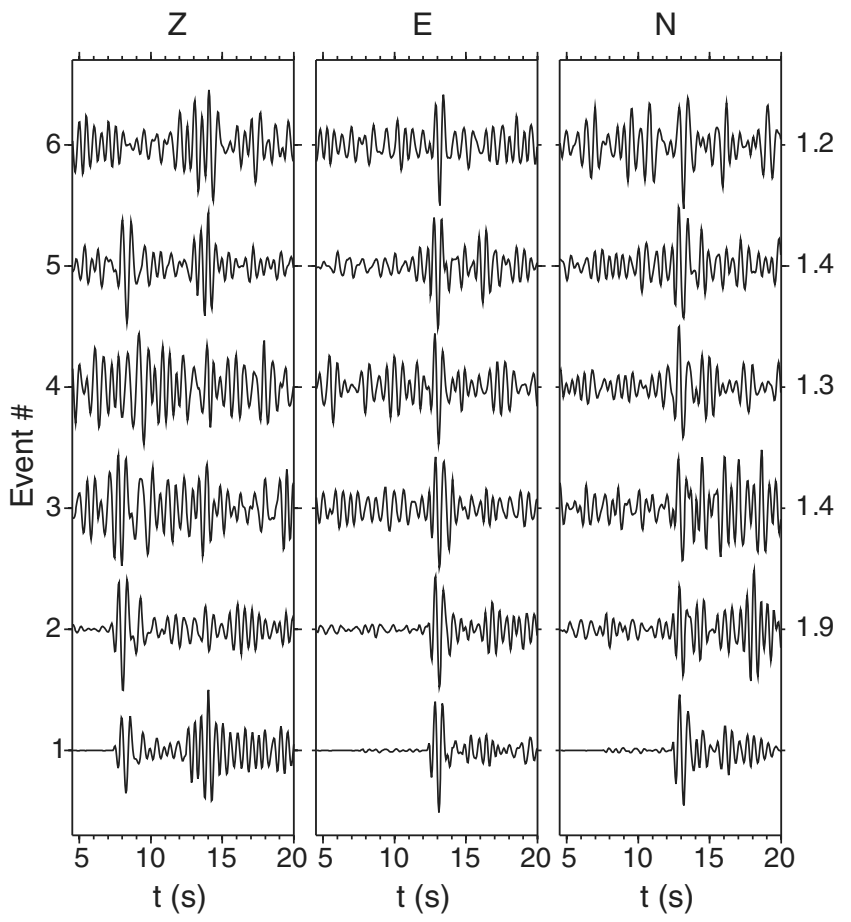

Figure 3. Three components (vertical, east, and north) of the template signal (trace number 1) and the SCC-detected events in Figure 2. Numbers on the right show the magnitudes estimated from amplitude ratios of the waveforms to those of the template event.

to the waveforms data. Another eight strong-motion stations (Fig. 1) of the CERI network were added in the process of the double-difference relocation to improve the relocation results. Data from the strong-motion stations were converted to velocity records and band-pass filtered from 1 to $6 \mathrm{~Hz}$.

\section{Event Detections by the SCC}

CERI located 37 events in the 2008 Illinois earthquake sequence, including the 18 April mainshock, 30 aftershocks in the first 2 weeks, and 6 aftershocks thereafter. We performed waveform cross correlation among all the events. Based on the waveform similarity, we divided these events into two groups. We selected one event from each group as the template. The two templates have magnitudes of $M_{\mathrm{L}} 3.3$ and 3.0, respectively. We then calibrated the SCC detection parameters, for example, the length of the template waveforms and threshold value of the SCC coefficient, by applying the SCC technique to the located events in the catalog. After the calibration, we chose the length of template waveforms to be $4 \mathrm{sec}$ (1 sec before and $3 \mathrm{sec}$ after the $S$ arrival). The SCC coefficient threshold was set to 0.6. By setting the previous parameters, we can detect all events in the catalog by the two templates. In order to detect small-magnitude aftershocks and maximize the number of detections, we only applied the SCC technique to the closest station OLIL, $37 \mathrm{~km}$ from the mainshock (Fig. 1). We set the smallest magnitude of events to be $M_{\mathrm{L}} 1.0$ because extremely small events would not have good waveform recordings at further distant stations so that there were not enough $P$ and $S$ arrivals to locate them later.

The SCC technique detected 151 aftershocks from 16 April to 2 May 2008 (see (E) additional material available in the electronic edition of BSSA). We only found three false detections after visually inspecting the waveforms. We did not find any foreshocks in this earthquake sequence from at least 2 days before the mainshock. Most aftershocks (100) occurred within 24 hrs after the mainshock. Decay in the number of aftershocks obeys Omori's law (Fig. 4). The magnitudes of aftershocks varied from $M_{\mathrm{L}} 1.0$ to 4.6 and the magnitude-frequency distribution follows the Gutenberg-Richter power law with a $b$-value of 0.6 (Fig. 4). Figure 4 also shows the magnitude-frequency distribution based on the events detected by the regional seismic network. It shows that the regional network earthquake catalog becomes incomplete at $M_{\mathrm{L}} \sim 4$. The largest aftershock that was missed by the catalog is an $M_{\mathrm{L}} 3.7$ event. It occurred 4 min after the mainshock so that its signals were buried in the coda of the mainshock.

\section{Double-Difference Relocations and Moment}

\section{Tensor Solutions}

We used the double-difference relocation algorithm to locate all the detected events. This relative relocation method uses differential travel times at the same station between two events and can effectively reduce location errors due to structural variations in the Earth (Waldhauser and Ellsworth, 2000). Twenty stations of the CNMSN and the CERI networks were used. Two stations, including OLIL, are within $40 \mathrm{~km}$ of the mainshock. Station coverage is fairly good in azimuth (Fig. 1). We first estimated the origin times of detected events based on the detection times at OLIL, calculated their theoretical $P$-wave arrival times at all stations, and extracted their waveforms. We then obtained accurate $P$ - and $S$-wave differential travel times between any two events at each individual station by waveform cross correlation. The measurement errors of the differential times were estimated to be less than $0.05 \mathrm{sec}$. In total we had $2877 P$ - and $7054 S$-wave differential time measurements.

Before we tried to relocate all the detected events, we tested the relocation algorithm with synthetic data to determine how reliably the observed differential travel times can locate the events. We put 151 artificial events randomly along a ring centered at the mainshock location on an arbitrarily oriented fault plane. We then generated synthetic differential travel times using a modified velocity model for the central United States (Table 1) (Herrmann, 1979). We added random noise of up to $0.1 \mathrm{sec}$ to the synthetic differential times. We found that the minimum number of observed differential times of event pairs (the minimum number of links) is critical for reliably locating events. For our synthetic data, some events would be located with large errors if the number were less than 6 . By requiring the minimum number of links 


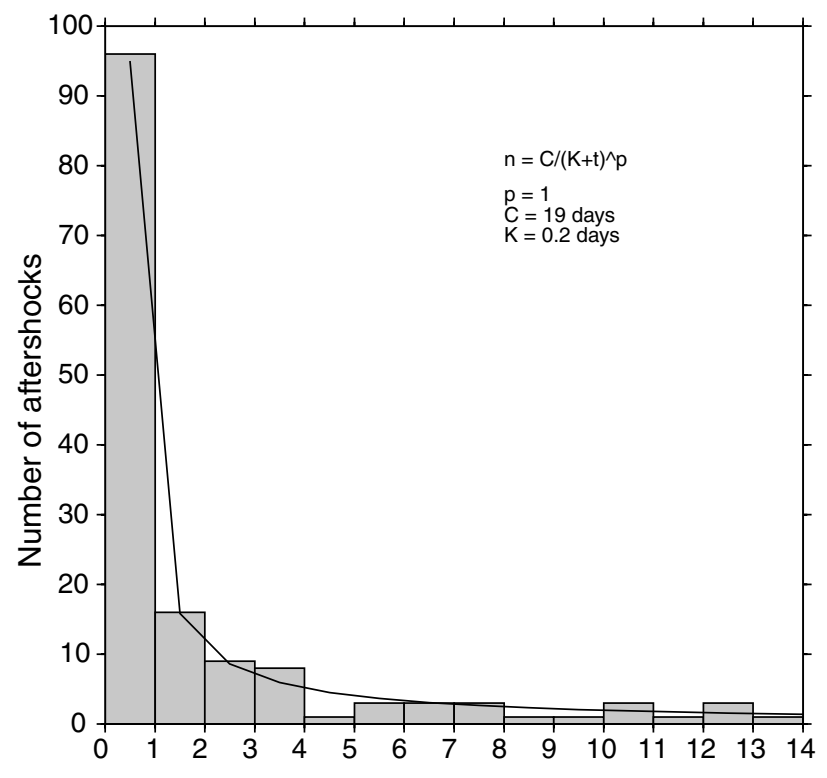

Day from the mainshock

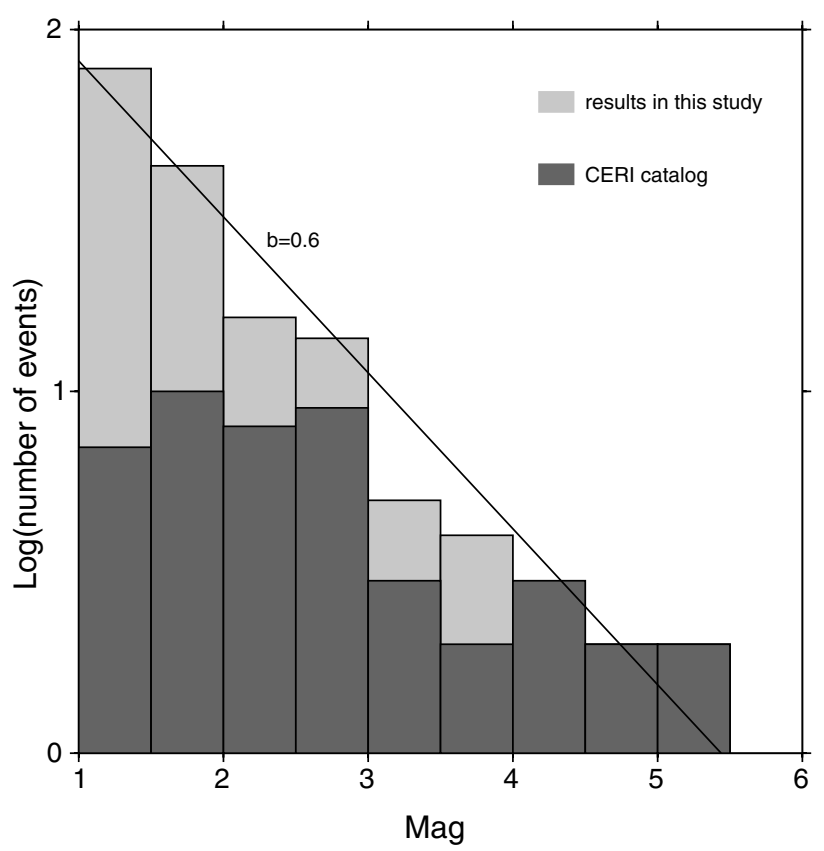

Figure 4. Temporal distribution of aftershocks in the first 2 weeks after the mainshock (left-hand panel). Magnitude-frequency distribution of the 18 April 2008 Illinois earthquake sequence (right-hand panel).

to be 6 , only 28 events are considered to be connected to form a cluster so that their locations can be solved by the double-difference method. Other events were discarded in the relocation process because they did not have enough differential travel-time observations to join in the cluster.

We then used the observed differential times to locate all the 28 aftershocks. It took 10 iterations to reduce the root mean square (rms) of travel-time residuals from 1.7 to $0.06 \mathrm{sec}$, a $96 \%$ rms reduction. The uncertainties of final locations of the 28 events are about $100 \mathrm{~m}$ in both horizontal and vertical directions.

Relocation results are plotted in Figure 5. All these events occurred within a narrow northwest-southeast trend, approximately $5 \mathrm{~km}$ in length. Our results agree with aftershock locations of Horton et al. (2008), who located more than 150 aftershocks using 14 temporary instruments deployed in the vicinity of the mainshock. We computed the fault-plane parameters by fitting all event locations with a plane by minimizing the L1 norm of the distances of events to the plane. The best-fit plane has a strike of $292^{\circ} \pm 11^{\circ}$ and is dipping to the northeast by $81^{\circ} \pm 7^{\circ}$. Event distribution

Table 1

Velocity Model Used in the Double-Difference Relocation

\begin{tabular}{ccc}
\hline Depth $(\mathrm{km})$ & $V_{P}(\mathrm{~km} / \mathrm{sec})$ & $V_{S}(\mathrm{~km} / \mathrm{sec})$ \\
\hline 0.0 & 5.00 & 2.89 \\
1.0 & 6.10 & 3.52 \\
10.0 & 6.40 & 3.70 \\
20.0 & 6.70 & 3.87 \\
40.0 & 8.15 & 4.70 \\
\hline
\end{tabular}

suggests that the fault extends from $\sim 10$ to $\sim 18 \mathrm{~km}$ in depth (Fig. 6).

Moment tensor solutions were computed for the mainshock and four largest aftershocks by the cut and paste method (Zhu and Helmberger, 1996). This method decomposes seismograms and uses amplitude information in different time windows (e.g., $\mathrm{Pnl} /$ surface wave) to increase the stability and resolution of focal mechanism solution. The Green's functions were computed using a Haskell propagator matrix method (Zhu and Rivera, 2002) and a modified velocity model for the central United States (Herrmann, 1979) (Table 1). We used the broadband waveform data from the CNMSN stations and applied a band-pass filter from 0.5 to $5 \mathrm{sec}$. Table 2 lists the focal mechanism solutions of the mainshock and four largest aftershocks. All these events have nearly vertical strike-slip focal mechanisms (Fig. 5). The strike of one of the fault planes agrees with the strike of the fault plane determined from the aftershock locations. By combining the moment tensor solutions and the relocation results, we conclude the fault causing the 18 April 2008 earthquake is a west-northwest-east-southeast-trending leftlateral strike-slip fault.

\section{Discussion}

The SCC method is very effective in detecting low SNR signals of small events, about one magnitude lower than the STA/LTA detector (Gibbons and Ringdal, 2006). It has been applied in exploration geophysics and in nuclear test monitoring by screening out well-known sources (e.g., quarry explosions) (Harris, 1991). Recently, it is also used to detect low-frequency earthquakes and nonvolcanic tremors (Shelly 


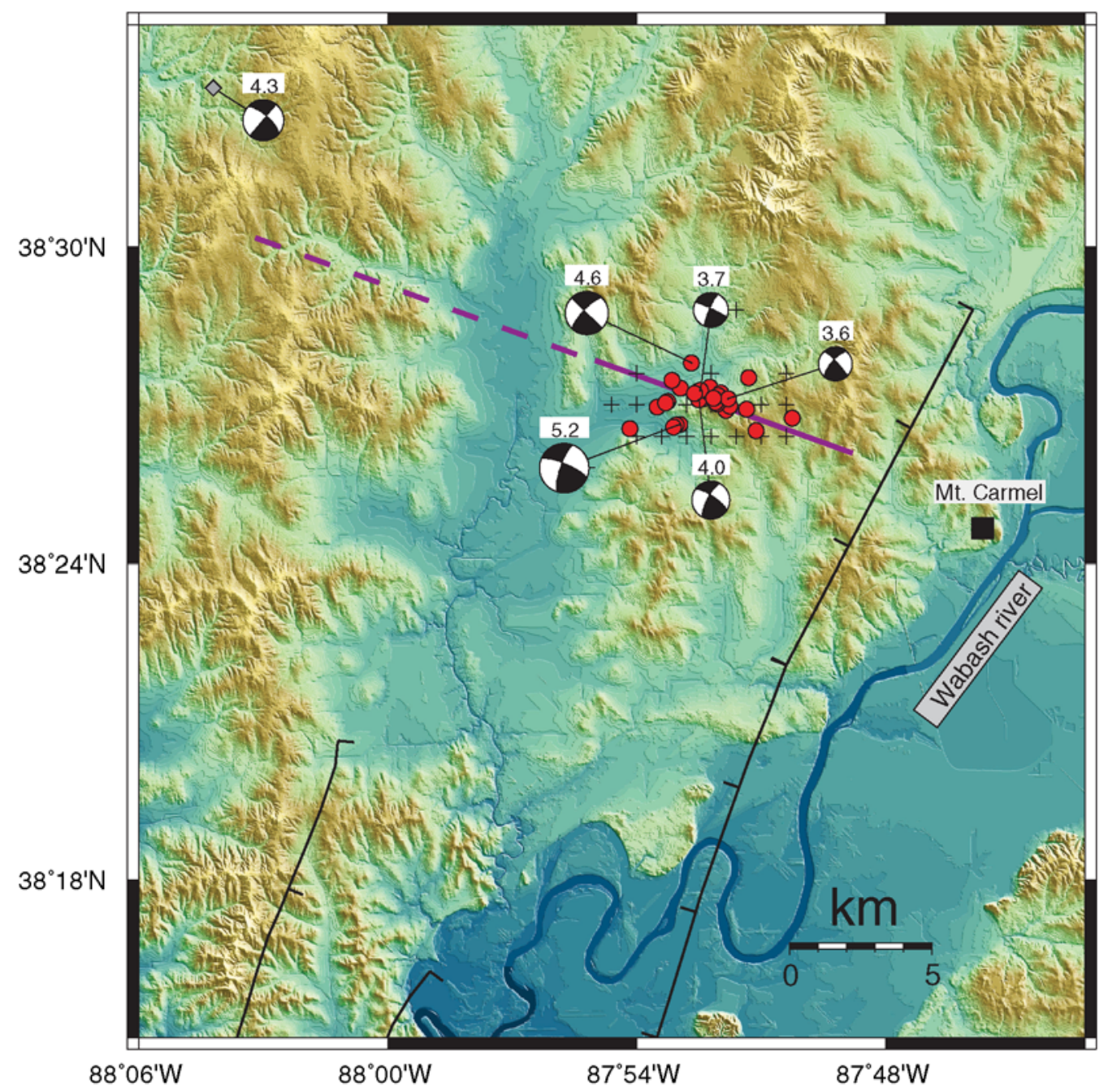

Figure 5. Red dots show locations of earthquakes located in this study. The straight line represents the estimated fault orientation $\left(292^{\circ}\right)$ from the locations. Black crosses are event locations in the CERI catalog. Mapped normal faults of the area are shown as black traces (ISGS, 1995). The gray diamond represents the location of an $M_{\mathrm{w}} 4.3$ earthquake that occurred in 1974.

et al., 2007a,b). This study shows that this technique is suitable for detecting aftershocks because they may have similar focal mechanisms and occurred in the vicinity of the mainshock. In particular, it can be efficiently used to detect aftershocks immediately following the mainshock, which are usually difficult to detect and to locate with conventional methods because of large background noise and overlapping arrivals from multiple events clustered in time. Here we found an $M_{\mathrm{L}} 3.7$ earthquake missing in the catalog because it was buried in the coda of the mainshock.

Detection by waveform cross correlation depends on the similarity of the template signal and waveform data that is controlled by focal mechanisms, propagation paths, and magnitudes of events. In general, aftershocks that occur on or near the mainshock fault plane have similar focal mechanisms. Separations between events in the aftershock cluster are small so that the propagation paths to seismic stations are nearly identical. The duration and complexity of the source time functions are mainly controlled by the event magnitude.
In this study, we band-pass-filtered waveform data between 0.3 and $8 \mathrm{~Hz}$, which are lower than the corner frequencies of earthquakes smaller than $M_{\mathrm{L}} 5$. Therefore, the influences of event magnitudes on waveform shapes were avoided.

In order to detect events as small as possible, we only applied the SCC technique to the closest station. False detections were greatly reduced by applying the SCC to threechannel recordings simultaneously. Technically, the detection threshold and false detections can be further reduced by combining detection results from multiple stations. We can stack the SCC coefficients of all stations to produce an array correlation beam (Gibbons and Ringdal, 2006). However, this kind of array technique requires a dense network, especially for small aftershocks. This aspect will be investigated in future studies.

Our relocation results and moment tensor solutions suggest that the 18 April 2008 earthquake occurred on a left-lateral, strike-slip fault with an orientation of $292^{\circ}$. The newly discovered fault lies southwest of Mount Carmel, 


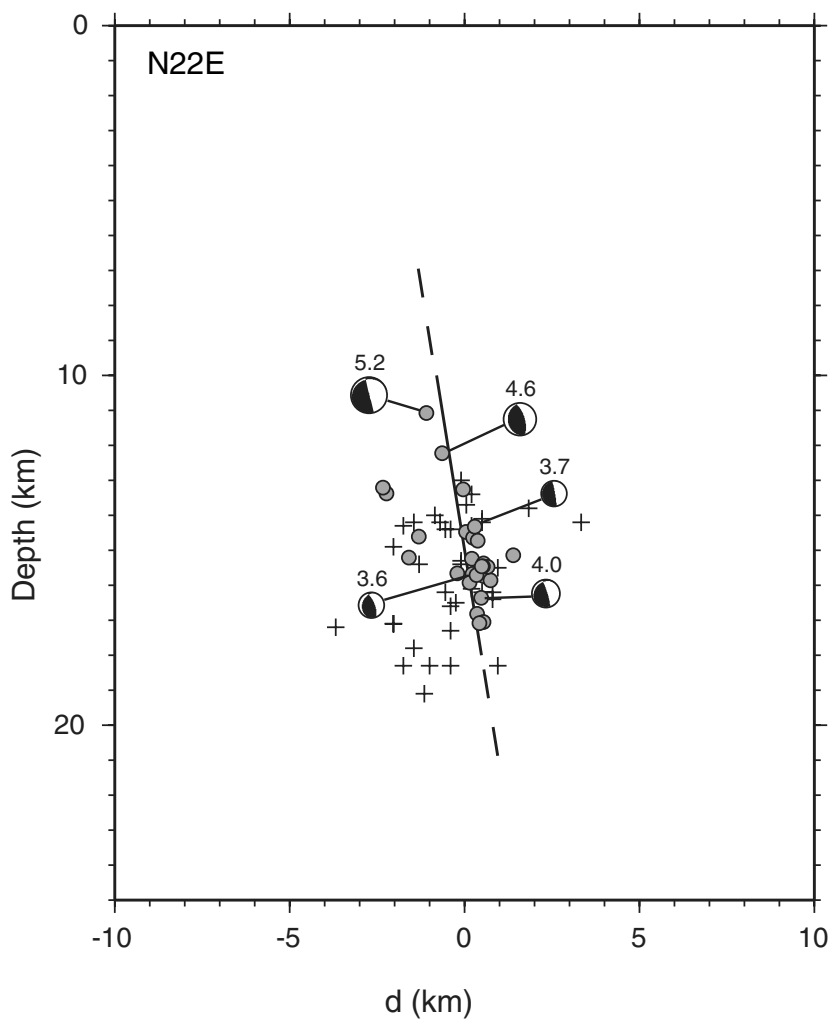

Figure 6. A vertical cross section oriented $\mathrm{N} 22^{\circ} \mathrm{E}$ across the fault. Gray dots show event locations determined in this study. The black line represents the fault plane inferred from the locations. The black crosses are locations in the CERI catalog.

Illinois (Fig. 5). Although its orientation differs significantly from the known northeast-southwest trend of normal faults in the region, the left-lateral, strike-slip faulting is consistent with the east-west compressional stress field in the region (Heidbach et al., 2008) (Fig. 1). Marshak and Paulsen (1996) proposed two northwest-trending, left-stepping accommodation zones that divided the northeast-trending La Salle deformation belt into the northern, central, and southern parts. Our newly discovered fault coincides with the southern accommodation zone (Divide). In addition, we speculate that the 3 April $1974 M_{\mathrm{w}} 4.3$ earthquake also occurred on this fault. Its focal mechanism (Herrmann, 1979) is similar to the moment tensor solutions of the 18 April 2008 earthquake sequence (Fig. 5). The seismicity on the fault indicates reactivation of old deformation zone by contemporary stresses.

Table 2

Moment Tensor Solutions for the Mainshock and Four Largest Aftershocks

\begin{tabular}{cccccc}
\hline $\begin{array}{c}\text { Date } \\
\text { (yyyymmdd) }\end{array}$ & $\begin{array}{c}\text { Time } \\
\text { (hhmmss) }\end{array}$ & $M_{\mathrm{w}}$ & Strike $\left({ }^{\circ}\right)$ & Dip $\left(^{\circ}\right)$ & Rake $\left(^{\circ}\right)$ \\
\hline 20080418 & 093700 & 5.2 & 295 & 76 & 14 \\
20080418 & 151416 & 4.6 & 314 & 90 & 15 \\
20080421 & 053829 & 4.0 & 304 & 74 & 18 \\
20080425 & 173100 & 3.7 & 295 & 85 & 10 \\
20080605 & 071314 & 3.6 & 316 & 82 & 18 \\
\hline
\end{tabular}

\section{Conclusions}

In summary, we have developed a reliable and efficient method to detect small-magnitude earthquakes using template events and waveform cross correlation. We found more than 120 aftershocks in the first 2 weeks following the 18 April 2008 Mount Carmel earthquake, more than three times the number reported by the permanent network with the traditional STA/LTA detector. We relocated 28 events by the double-difference relocation algorithm and found that these events were located on a nearly vertical plane striking westnortwest-east-southeast. By combining the relocation results with focal mechanism solutions, we conclude that the fault responsible for the 18 April earthquake is a left-lateral, strike-slip fault with an orientation of $292^{\circ}$ and a dip angle of $81^{\circ}$. The fault coincides with one of the proposed leftstepping accommodation zones (Divide) in the La Salle deformation belt and indicates reactivation of an old deformation zone by contemporary stresses in the midcontinent.

\section{Data and Resources}

Waveform data from Cooperative New Madrid Seismic Network are available at IRIS data center, http://www.iris.edu (last accessed October 2008).

\section{Acknowledgments}

The authors thank editor Ivan G. Wong and two anonymous reviewers for their valuable comments that improved the manuscript greatly. We benefited from discussions with Robert B. Herrmann and John Encarnicion of Saint Louis University. We also thank Abuduwasiti Wulamu of Saint Louis University for helping to visualize 3D relocation results. This work is supported by the National Science Foundation under Grant Number EAR0609969.

\section{References}

Ault, C. H., and D. M. Sullivan (1982). Faulting in southwest Indiana, U.S. Nuclear Regulatory Commission Report, Tech. Rep. NUREG/CR2908, Indiana Geological Survey.

Ault, C. H., D. Harper, C. R. Smith, and M. A. Wright (1985). Faulting in jointing in and near surface mines of southwest Indiana, Tech. Rep. NUREG/CR-4117, Indiana Geological Survey.

Duchek, A. B., J. H. McBride, W. J. Nelson, and H. E. Leetaru (2004). The Cottage Grove fault system (Illinois basin): Late Paleozoic transpression along a Precambrian crustal boundary, Geol. Soc. Am. Bull. 116, 1465-1484.

Eagar, K. C., G. L. Pavlis, and M. W. Hamburger (2006). Evidence of possible induced seismicity in the Wabash Valley seismic zone from improved microearthquake locations, Bull. Seismol. Soc. Am. 96, 17181728.

Frankel, A., C. Mueller, T. Barnhard, D. Perkins, E. Leyendecker, N. Dickman, S. Hanson, and M. Hopper (1996). National seismic-hazard maps: Documentation June 1996, U.S. Geol. Surv., Tech. Rep. 96-532.

Frankel, A., M. D. Petersen, C. Mueller, K. M. Haller, R. L. Wheeler, E. V. Leyendecker, R. L. Wesson, S. C. Harmsen, C. H. Cramer, D. M. Perkins, and S. Rukstales (2002). Documentation for the 2002 update of the national seismic hazard maps, U.S. Geol. Surv., Tech. Rep. 02-420.

Freiberger, W. F. (1963). An approximation method in signal detection, Quart. J. Appl. Math. 20, 373-378. 
Gibbons, S. J., and F. Ringdal (2006). The detection of low magnitude seismic events using array-based waveform correlation, Geophys. J. Int. 165, 149-166.

Gomberg, J., and E. Schweig (2002). Earthquake hazard in the heart of the homeland, U.S. Geological Survey Fact Sheet FS-131-02.

Harris, D. B. (1991). A waveform correlation method for identifying quarry explosions, Bull. Seismol. Soc. Am. 81, 2395-2418.

Heidbach, O., M. Tingay, A. Barth, J. Reinecker, D. Kurfeß, and B. Muller (2008). The Release 2008 of the World Stress Map: available at www .world-stress-map.org (last accessed May 2009).

Herrmann, R. B. (1973). Surface-wave generation by the south central Illinois earthquake of November 9, 1968, Bull. Seismol. Soc. Am. 63, 2121-2134.

Herrmann, R. B. (1979). Surface wave focal mechanisms for eastern North American earthquake with tectonic implications, J. Geophys. Res. 84, 3543-3552.

Herrmann, R. B., M. Withers, and H. Benz (2008). The April 18, 2008 Illinois earthquake: An ANSS monitoring success, Seism. Res. Lett. 79, 830-843.

Horton, S., S. Ayele, H. Deshon, M. Withers, T. Stigall, G. Pavlis, and M. Hamburger (2008). Aftershocks of the $M_{\mathrm{w}} 5.2$ April 18, 2008, Mt. Carmel, Illinois Earthquake, The Eastern Section of the Seismological Society of America Meeting Abstract, Ontario, Canado, October 2008.

Illinois State Geological Survey (ISGS) (1995). Structural features in Illinois-1995-Faults: ISGS GIS Database, Illinois State Geological Survey, Champaign, Illinois.

Kim, W.-Y. (2003). The 18 June 2002 Caborn, Indiana, earthquake: Reactivation of ancient rift in the Wabash Valley seismic zone?, Bull. Seismol. Soc. Am. 93, 2201-2211.

Langer, C. J., and G. A. Bollinger (1991). The southeastern Illinois earthquake of 10 June 1987: The later aftershocks, Bull. Seismol. Soc. Am. 81, 423-445.

Marshak, S., and T. Paulsen (1996). Midcontinent U.S. fault and fold zones; a legacy of Proterozoic intracratonic extensional tectonism?, Geology 24, 151-154.

McBride, J. H., T. G. Hildenbrand, W. J. Stephenson, and C. J. Potter (2002). Interpreting the earthquake source of the Wabash Valley seismic zone (Illinois, Indiana, and Kentucky) from seismic-reflection, gravity, and magnetic-intensity data, Seism. Res. Lett. 73, 660-686.

McBride, J. H., H. E. Leetaru, R. A. Bauer, B. E. Tingey, and S. E. A. Schmidt (2007). Deep faulting and structural reactivation beneath the southern Illinois basin, Precambrian Res. 157, 289-313.

Mueller, K., S. E. Hough, and R. Bilham (2004). Analysing the 1811-1812 New Madrid earthquakes with recent instrumentally recorded aftershocks, Nature 429, 284-289.

Nuttli, O. W. (1979). Seismicity of the central United States, Rev. Eng. Geol. 4, 67-94.

Obermeier, S. F., N. R. Bleuer, C. A. Munson, P. J. Munson, W. S. Martin, K. M. McWilliams, D. A. Tabaczynski, J. K. Odum, M. Rubin, and D. L. Eggert (1991). Evidence of strong earthquake shaking in the lower Wabash Valley from prehistoric liquefaction features, Science 251, 1061-1063.
Pratt, T. L., E. C. Hauser, and K. D. Nelson (1992). Widespread buried Precambrian layered sequences in the U.S. Mid-Continent evidence for large Proterozoic depositional basins, Am. Assoc. Petrol. Geol. Bull. 76, 1384-1401.

Rene, R. M., and F. L. Stanonis (1995). Reflection seismic profiling of the Wabash Valley fault system in the Illinois basin, in Investigations of the New Madrid Seismic Zone, U.S. Geol. Surv., Tech. Rep. 1538-O.

Shelly, D. R., G. C. Beroza, and S. Ide (2007a). Non-volcanic tremor and low-frequency earthquake swarms, Nature 446, 305-307.

Shelly, D. R., G. C. Beroza, and S. Ide (2007b). Complex evolution of transient slip derived from precise tremor locations in western Shikoku, Japan, Geochem. Geophys. Geosyst. 8, 640, doi 10.1029/2007GC001.

Stauder, W., and O. Nuttli (1970). Seismic studies: South central Illinois earthquake of November 9, 1968, Bull. Seismol. Soc. Am. 60, 973-981.

Taylor, K. B., R. B. Herrmann, M. W. Hamburger, G. L. Pavlis, A. Johnston, C. Langer, and C. Lam (1989). The southeastern Illinois earthquake of 10 June 1987, Seism. Res. Lett. 60, 101-110.

U.S. Geological Survey (USGS) and Illinois State Geological Survey (ISGS) (2006). Quaternary fault and fold database for the United States: available from USGS at http://earthquake.usgs.gov/regional/qfaults, U.S. Geological Survey and Illinois State Geological Survey (last accessed May 2008).

van Trees, H. L. (1968). Detection, Estimation and Modulation Theory, John Wiley and Sons, Inc., New York, 249 pp.

Waldhauser, F., and W. L. Ellsworth (2000). A double-difference earthquake location algorithm: Method and application to the northern Hayward fault, California, Bull. Seismol. Soc. Am. 90, 1353-1368.

Whalen, A. D. (1971). Detection of Signals in Noise, Academic Press, New York, 167-179.

Wheeler, R. L., and D. Ravat (2002). Introduction: Seismicity, Quaternary faulting, and seismic hazard, Seism. Res. Lett. 73, 590-596.

Woolery, E. W. (2005). Geophysical and geological evidence of neotectonic deformation along the Hovey Lake fault, Lower Wabash Valley fault system, central United States, Bull. Seismol. Soc. Am. 95, 1193-1201.

Zhu, L., and D. V. Helmberger (1996). Advancement in source estimation techniques using broadband regional seismograms, Bull. Seismol. Soc. Am. 86, 1634-1641.

Zhu, L., and L. A. Rivera (2002). A note on the dynamic and static displacements from a point source in multilayered media, Seism. Res. Lett. 148, $619-627$.

Department of Earth and Atmospheric Sciences

Saint Louis University

St Louis, Missouri 63108

(H.Y., L.Z.)

Seismological Lab

California Institute of Technology

Pasadena, California 91125

(R.C.)

Manuscript received 11 February 2009 